\title{
Oncoplastic Breast Surgery in Early Breast Cancer
}

\section{Ahmed T. Abdelaziz ${ }^{\mathrm{a}}$, Mahmoud A. Mahmoud ${ }^{\mathrm{a}}$,Asmaa G. Rizk ${ }^{\mathrm{a}}$, Mohammed A. Negm ${ }^{\mathrm{a}}$ \\ ${ }^{a}$ General Surgery Department, Faculty of Medicine, South Valley University-Qena, Egypt.}

\begin{abstract}
Oncoplastic medical procedure consolidates plastic careful systems with sound careful oncologic standards. The objective is to totally extract the malignant growth, with wide careful edges while keeping up or improving cosmesis. For huge, inadequately characterized, or ominously arranged tumors, standard lumpectomies may prompt unsuitable restorative outcomes notwithstanding close or included resection edges. Comparable issues may happen for littler tumors in little bosoms. Joining of the two careful orders evades or limits poor restorative outcomes after wide extraction. It builds the quantity of ladies who can be treated with breast-conserving medical procedure by permitting bigger bosom extractions with progressively satisfactory corrective outcomes. Oncoplastic medical procedure requires a multidisciplinary approach and exhaustive preoperative arranging. It is totally important to enroll the participation and coordination of careful oncology, plastic medical procedure, radiology, pathology, restorative oncology, and radiation oncology. Oncoplastic medical procedure requires a way of thinking that the presence of the bosom after tumor extraction is significant.
\end{abstract}

Keywords: oncoplastic breast surgery; oncoplastic breast conservation; reduction excision; breast cancer oncoplastic surgery.

\section{Introduction}

Breast cancer is the commonest cancer in females and although the mortality is decreasing (Baildam,2002) the screening program detects presymptomatic breast pathology in an increasing number of women (Parkin et al., 1992) The result of increased detection is a higher demand for intervention. Media interest and heightened awareness has also encouraged higher expectations. If we are to meet these expectations funding must be made available to optimize service organisation, availability of reconstruction and training. For selected women diagnosed with breast cancer, randomised trials have shown equivalent long-term survival for those treated with breast-conserving surgery combined with post-operative radiotherapy and those treated with mastectomy (Fisher et al.,2002;Veronesi et al.,2001) Breast conserving surgery has potential advantages of better cosmesis and body image (Veronesi et al.,1990;Clough et al., 1999) However, results often fall below surgical and patient expectations. (Shrotria, 2001; Noguchi et al., 1991) Partial breast reconstructive techniques are increasingly being used to improve these outcomes. In general, these techniques involve breast 
reshaping or volume replacement and frequently include contra-lateral surgery. They often allow for wider local tumor excision, potentially reducing the incidence of margin involvement.(Veronesi et al., 1990) and may enhance the cosmetic outcome. The ability to excise a wider margin may be important in certain subgroups of patients (e.g. patients with DCIS). Also, this may allow excision of larger tumors that would normally be treated by mastectomy. The aim of this article is to review the oncological and cosmetic outcomes of studies where partial breast reconstructive techniques have been used. There are four corners construct oncoplastic breast surgery: appropriate surgery to eradicate the cancer, partial re-construction to correct wide excision defect, immediate reconstruction using several available techniques and correction of asymmetry relative to contralateral breast. All of these require adequate planning with respect to the placement and closure of the wound.

\section{Breast Reshaping}

Different methods of parenchymal redistribution have been described to fill small or moderate defects in the breast. (Clough et al., 1999; Shrotria, 2001) These all fundamentally rely on advancement, rotation or transposition of a large area of breast to fill the defect. This effectively absorbs the volume loss over a much larger area, thus decreasing the risk of a localized defect. In its simplest form this may entail mobilizing the breast plate from the area immediately around the excision up to whole breast plate mobilization, depending on the size of the defect. Other methods of breast tissue redistribution include the use of local tissue flaps such as the Grisotti advancement rotation flap, which may be used to fill central defects. (Galimberti et al., 1993)or lateral rotation flaps for lateral defects(Clough et al., 1999;Masetti et al., 2000). Using breast reduction techniques to excise cancers can be a good option in selected patients. The ideal patient is one where the tumor can be excised within the expected breast reduction excision and for whom a smaller breast size is viewed as a positive outcome. However, modifications of these techniques to treat cancers that lie outside of expected excisions is increasingly being advocated (Clough et al.,1999;McCulleyet al.,2005).This requires sound knowledge of different mammoplasty techniques, incisions and pedicles. From an oncological view, these techniques allow wide local excision, potentially decrease the risk of margin involvement and recurrence.

\section{One- or two-stage breast reshaping}

The advantage of performing a one- or two-stage procedure is debated (Clough et al., 2004; Papp et al., 1998). Frequently a very large excision may be taken with the mammoplasty and the chances of incomplete excision are very small. If margins are involved in such cases, the extent of disease will probably dictate that a mastectomy is the most appropriate treatment option and not re-excision. This, combined with the advantage of limiting the number of surgical procedures, favors a onestage procedure. (Hamdi et al., 2004) Twostage procedures can be delayed-immediate (initial wide local excision and then mammoplasty 2-3 weeks later when the histological margin assessment has been performed) or true-delayed ('corrective' 
mammoplasty in those with a poor result after completing wide local excision and radiotherapy.(Clough et al., 2004). The potential disadvantages of two-stage procedures relate to the difficulties and complications of operating on a previously treated breast, i.e scar tissue, radiotherapy changes and fibrosis. However, the advantages are that some women may not deem further surgery necessary. As opposed to breast reshaping the concept of immediate breast volume replacement after breastconserving surgery using the latissimusdorsi muscle was first described by Noguchi (Noguchi et al., 1992). In patients with a carcinoma of the upper outer quadrant, the entire quadrant was removed together with the overlying skin and underlying pectoralis fascia. Axillary dissection was performed through the same incision. In patients with carcinomas of the inner quadrant, quadrantectomy and axillary dissection were performed separately. The latissimus dorsi muscle was partially dissected through the quadrantectomy or axillary wound as a musculosubcutaneous flap that was then transposed onto the anterior chest.

\section{The contralateral breast}

At the point when evenness is wanted, the contralateral bosom will for the most part should be balanced. This should be possible during a similar employable system as the underlying malignant growth or as a deferred strategy. The benefit of doing the two sides at the same time is a solitary usable methodology. The detriment is that the last pathology and specifically, the edge status, is obscure before adjusting the presence of the contrary bosom. In any case, if the patient concludes that she is happy to acknowledge the dangers of close or positive edges (that may require reoperation) and would incline toward a solitary activity (and most patients do), the contralateral side can be balanced at a similar activity. It is insightful to leave the infected bosom unobtrusively bigger than the contralateral bosom, to represent some shrinkage that happens after adjuvant radiotherapy (Munhoz et al., 2007).

\section{One or two stage volume replacement}

As with breast reshaping techniques, worries about margin involvement have dictated whether a one or two stage approach is used in volume replacement techniques. Rainsbury has advocated a onestage approach, whereby bed-biopsies are taken from the cavity wall and subareolar region after tumor resection and these sent for frozen section analysis. The entire cavity is then re excised (after inking) as a continuous shaving and this sent for formal histology. If any bed biopsies are found to contain tumor on frozen section analysis, a further set of bed biopsies is taken following the re-excision of the cavity wall. If tumor is present in the second set of bed biopsies, this indicates the need for mastectomy. This can be carried out as a one-stage procedure combined with LD reconstruction in a fully consented patient(Rainsbury,2002). Alternatively, the operation is planned and performed as a two-stage procedure. In the first stage, a partial mastectomy and formal histological margin analysis is performed. If the margins are clear, a partial breast reconstruction is performed 1-2 weeks later.

(Dixon et al., 2002). 


\section{Conclusion}

Oncoplastic breast surgery is an alternative option for women who choose it. The measurable outcomes of breast-conserving surgery are survival, local recurrence rates, cosmesis and patient satisfaction. Oncoplastic breast conserving surgery can be technically demanding, time consuming and does need specialist training to learn and apply properly, which may have cost and resource implications for individual hospitals. However, there is an increasing demand for surgeons with experience and training in this sub-speciality and specialist training opportunities in oncoplastic breast surgery are presently being offered in many breast units.The most selected women are with small cancers relative to breast size where a small percentage of the breast is excised. This accounts for perhaps the majority of women currently offered breastconserving surgery.

\section{References}

Baildam AD. (2002). Oncoplastic surgery of the breast. Br J Surg., 89: 532-533.

Clough KB, Kroll SS, Audretsch W.(1999).An approach to the repair of partial mastectomy defects.PlastReconstrSurg, 104:409-20.

Clough KB, Kroll SS, Audretsch W. (1991).An approach to the repair of partial mastectomy defects.PlastReconstrSurg, 104:409-20.

Clough KB, Thomas SS, Fitoussi AD, Couturaud B, Reyal F, Falcou MC.(2004). Reconstruction after conservative treatment for breast cancer: cosmetic sequelae classification revisited. PlastReconstrSurg, 114:1743-53.
Dixon JM, Venizelos B, Chan P.(2002). Latissimus dorsi mini-flap: A technique for extending breast conservation. Breast, $11: 58-65$.

Fisher B, Anderson S, Bryant J, Margolese RG, Deutsch M, Fisher ER, et al., (2002). Twenty-year follow-up of a randomized trial comparing total mastectomy, lumpectomy, and lumpectomy plus irradiation for the treatment of invasive breast cancer. N Engl J Med, 347:1233-41.

Galimberti V, Zurrida S, Zanini V, Callegari M, Veronesi P, Catania S, et al., (1993).Central small size breast cancer, how to overcome the problem of nipple and areola involvement.Eur J Cancer, 29A:1093. Hamdi M, Van Landuyt K, Monstrey S, Blondeel P.(2004).Pedicled perforator flaps in breast reconstruction: a new concept. Br J PlastSurg, 57:531-9.

Masetti R, Pirulli PG, MagnoS,Franceschini G, Chiesa F, Antinori A.(2000).Oncoplastic techniques in the conservativesurgical treatment of breast cancer. Breast Cancer, 7: 276-80.

McCulley SJ, Durain P, Macmillan RD.(2005).Therapeutic mammoplasty for centrally located breast tumours.PlastReconstrSurg, in press.

Munhoz A, Filassi JR, Aldrighi C, Ricci MD, Martella E, de Barros AC, Gamerli R, Ferreira MC.(2007). Bilateral reduction mammoplasty for immediate breast conservation surgery reconstruction and intraoperative radiotherapy: A preliminary report. AesthPlastSurg, 31:94-100.

Noguchi M, Saito Y, Mizukami Y, Nonomura A, Ohta N, Koyasaki N, et al., (1991).Breast deformity, its correction, and 
assessment of breast conserving surgery. Breast Cancer Res Treat, 18:111-8.

Noguchi M, Saito Y, Taniya T, Kitagawa H, Ohta N, Earashi M, et al., (1992).Wide resection with latissimusdorsi muscle transposition in breast conserving surgery.SurgOncol, 1:231-6.

Parkin DM, Muir CS, Whelan SL, Gao YT, Ferlay J, Powell J. (1991).Cancer incidence in five continents. IARC SciPubl, 120(6): 178-861.

Papp C, Wechselberger G, Schoeller T.(1998).Autologous breast reconstruction after breast-conserving cancer surgery.PlastReconstr Surg;102:1932-6.

Rainsbury RM.(2002).Breast-sparing reconstruction with latissimusdorsiminiflaps.Eur J SurgOncol, 28:891-5.

Shrotria S. (2001).Techniques for improving the cosmetic outcome of breast conserving surgery.Eur J SurgOncol, 27: 109-12.

Veronesi U, Marubini E, Mariani L, Galimberti V, Luini A, Veronesi P et al., (2001). Radiotherapy after breast-conserving surgery in small breast carcinoma: Longterm results of a ranodomized trial. Ann Oncol,12:997-1003.

Veronesi U, Volterrani F, Luini A, Saccozzi R, Del Vecchio $M$, Zucali R, et al., (1990).Quadrantectomy versus lumpectomy for small size breast cancer.Eur J Cancer, 26:671-3. 